\title{
Calçadas Drenantes: Intervenções físicas com desenvolvimento social
} Draining pavements: physical interventions with social development

\author{
Daniella Naomi Yamana \\ Universidade de São Paulo, Faculdade de \\ Arquitetura e Urbanismo, Brasil \\ daniella.yamana@usp.br
}

\section{Jady Medeiros}

Universidade São Judas Tadeu, Faculdade de Arquitetura e Urbanismo, Brasil

jady.mms@gmail.com

\section{Eduardo Ignacio Lopes}

Universidade de São Paulo, Faculdade de Arquitetura e Urbanismo, Brasil eilopes@usp.br

\section{Paulo Eduardo Fonseca de Campos}

Universidade de São Paulo, Faculdade de Arquitetura e Urbanismo, Brasil

pfonseca@usp.br

\begin{abstract}
This work presents the development of an applied research related to the installation of rainwater drainage systems in areas of economic and social vulnerability in São Paulo City, Brazil. It is also relevant for us to encourage participatory processes that involve the local community in problem-solving activities, while allowing appropriation of the technology applied. In this case, we are employing light prefabrication based on high performance microconcrete, molded in formwork produced with the aid of digital manufacturing. Our main purpose is to promote urban improvements in precarious settlements along with local economic development, made possible by self-management and community production.
\end{abstract}

Keywords: Collaborative urbanism; Urban drainage; Microconcrete; Digital fabrication.

\section{Introdução}

Este trabalho apresenta o desenvolvimento de pesquisa aplicada voltada a explorar as possibilidades do uso da fabricação digital em projetos de infraestrutura urbana. Com esse intuito vem sendo desenvolvida uma proposta para a produção de módulos pré-fabricados de microconcreto de alto desempenho, cujos moldes serão executados com o uso de uma fresadora CNC. A proposta prevê a posterior transferência da tecnologia às comunidades residentes em bairros da periferia de São Paulo, que constituem a população-alvo do projeto. A seguir são apresentadas as etapas do processo de investigação e prototipagem do sistema construtivo denominado "Calçadas Drenantes" no contexto urbano de áreas de alta vulnerabilidade social e ambiental, a fim de buscar solucionar não só a questão técnica da drenagem de águas superficiais, mas também de modo a fomentar o desenvolvimento de uma alternativa de geração de emprego e renda nestas localidades.

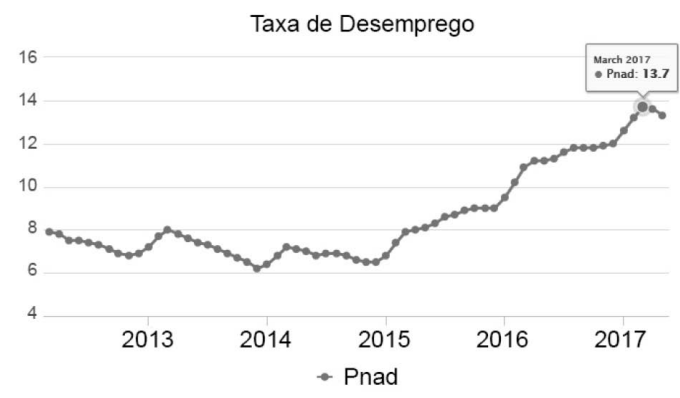

Figura 1: Gráfico da taxa de desemprego no Brasil - proporção entre a população desempregada e a população economicamente ativa - Pesquisa Nacional por Amostra de Domicílios Contínua. Fonte: PNAD 2013 a 2017. Elaborado por ADVFN Brasil.

\section{O contexto da intervenção}

A ocupação irregular recente em áreas de vulnerabilidade social e ambiental tem origem em uma dinâmica de "periferização" que se confunde com a própria formação das cidades no Brasil, decorrente do empobrecimento da população, da demanda por moradia e do crescimento acelerado do desemprego (Figura 1).

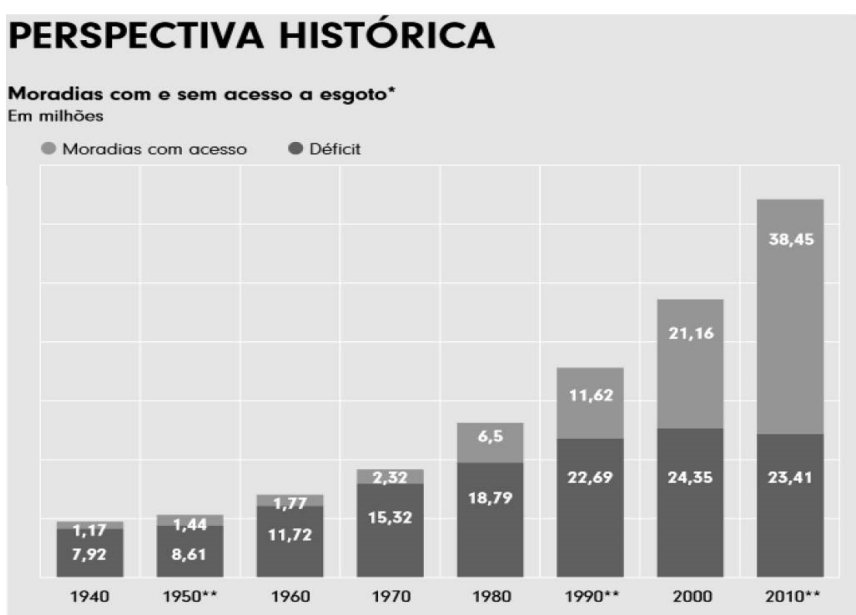

Figura 2: Gráfico comparativo do número de moradias com e sem acesso a esgoto no Brasil por ano. Fonte: Instituto Trata Brasil/ FGV.

Esse processo vem intensificando a desigualdade social e a segregação sócio-espacial; impactando diretamente na qualidade de vida e privando parte considerável dos cidadãos de seus direitos básicos. Por exemplo, de acordo com o levantamento realizado em 2010 pelo Instituto Trata Brasil, quase metade da população brasileira não tinha acesso a 
saneamento básico na ocasião (Figura 2), realidade que ainda permanece e se agrava a cada ano.

Muitas destas áreas vulneráveis encontram-se próximas a cursos d'água e mananciais, caso das comunidades alvo aqui focalizadas, residentes nos bairros Jardim Lapenna e Jardim Pantanal, ambos localizados junto à várzea do Rio Tietê, na Zona Leste da cidade de São Paulo (Figura 4). O intuito da proposta aqui apresentada é, portanto, oferecer uma alternativa a esse tipo de condição, e assim, minimizar os danos e riscos causados pelas inundações recorrentes. A alternativa desenvolvida para esse problema foi a utilização de módulos pré-fabricados leves em microconcreto, projetados de forma a favorecer a transferência de tecnologia e a participação comunitária.

O sistema construtivo apresentado teve sua origem em 2006, por meio de uma ação ocorrida no âmbito do PIAI - Programa de Integração de Assentamentos Irregulares, vinculado ao Ministerio de Vivienda, Ordenamiento Territorial y Medio Ambiente (MVOTMA) do Uruguai. Na concepção original do projeto estava prevista a criação de unidades de produção designadas como CPC - Centro de Produção Comunitária as quais seriam responsáveis pela produção de elementos pré-fabricados de microconcreto voltados para a construção de infraestrutura e equipamentos urbanos em zonas periféricas de diversas cidades uruguaias.

A partir dessa experiência foram obtidos resultados satisfatórios na prototipagem dos componentes da calçada drenante que, mesmo produzidos com métodos convencionais - fôrmas de madeira executadas em carpintaria tradicional - e em condições não ideais, alcançaram o desempenho estrutural e a qualidade desejados (Figura 3).

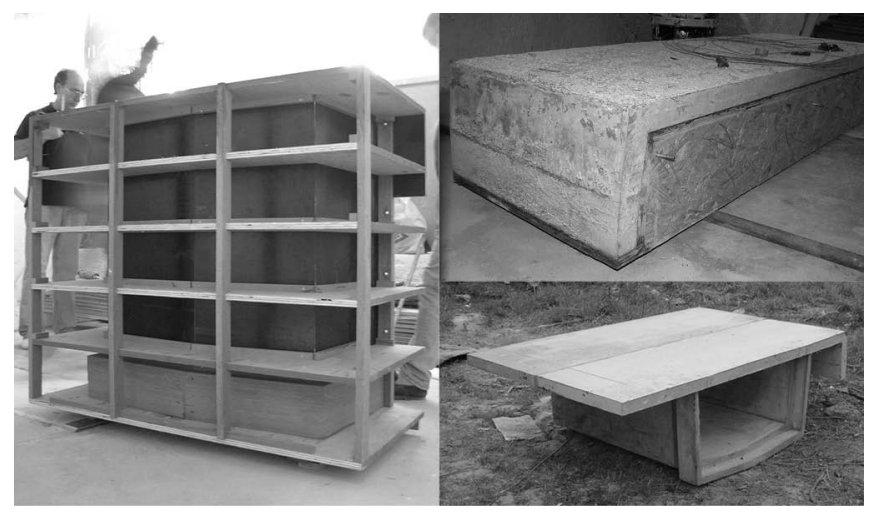

Figura 3: Execução do protótipo da calçada drenante em um centro comunitário na periferia de Montevidéu, Uruguai, em 2006. Fonte: Paulo Eduardo Fonseca de Campos.

Uma oportunidade de dar continuidade ao trabalho desenvolvido no Uruguai foi justamente a aplicação do sistema construtivo à realidade de periferias paulistanas, que também sofrem com o problema do manejo de águas e drenagem. Além disso, viu-se aí a possibilidade de incorporar novas técnicas de fabricação digital na construção do sistema, a fim de facilitar a replicação do modelo e transferência de conhecimento técnico. Para tornar o projeto viável neste âmbito, conta-se atualmente com a participação da rede municipal Fab Lab Livre SP, implantada há cerca de dois anos na cidade de São Paulo e reconhecida atualmente como a maior rede pública de laboratórios de fabricação digital no mundo, constituída por 12 unidades (Figura 4).

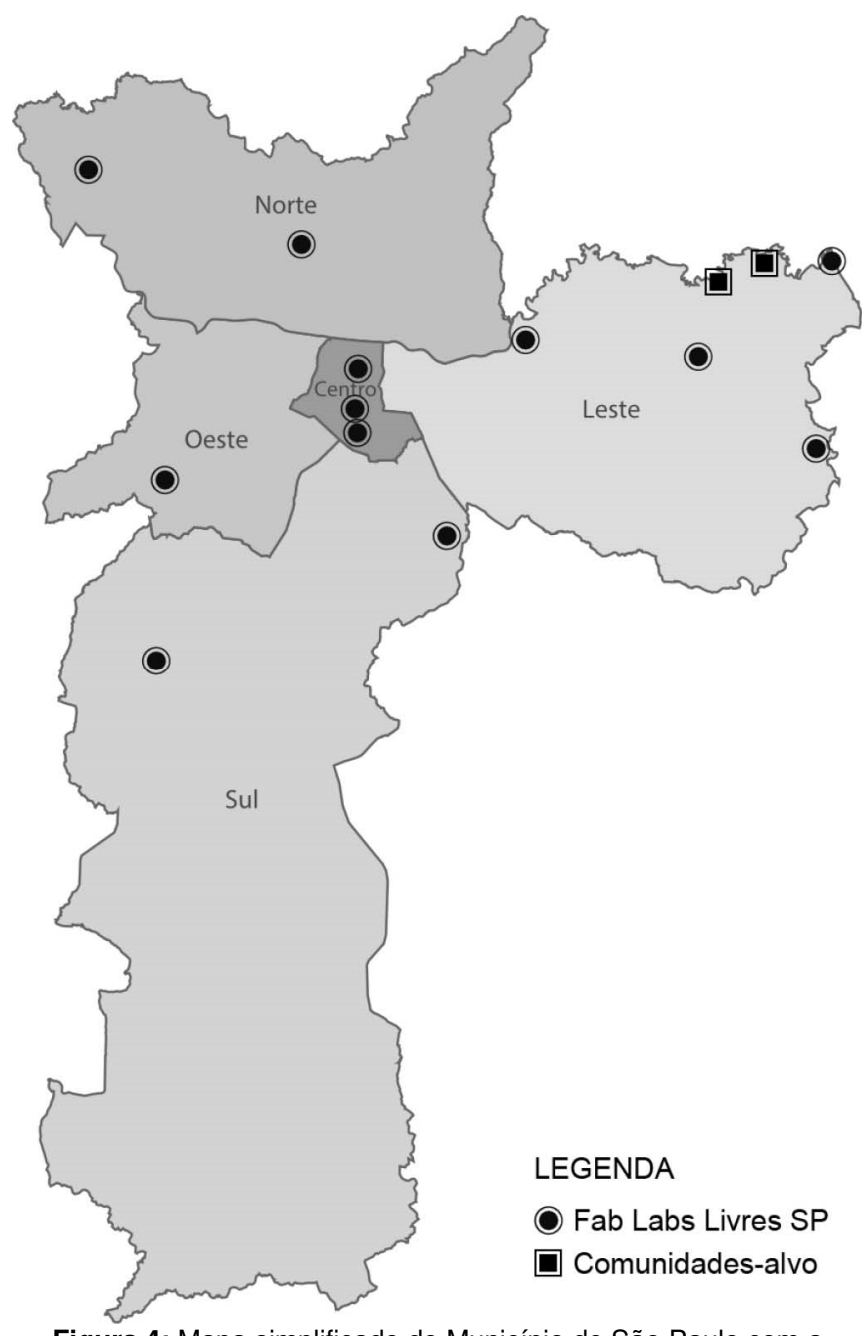

Figura 4: Mapa simplificado do Município de São Paulo com a localização das unidades Fab Lab Livre SP e das comunidades-alvo do projeto "Calçadas Drenantes". Fonte: Vinícius H. Ladivez e Guilherme Queiroz.

A aplicação prática do sistema construtivo de pré-fabricados leves para infraestruturas se dará nos chamados "canteiros experimentais", unidades de produção comunitária implantadas no âmbito do Projeto "ZL Vórtice", em atividade desde 2015. O convênio estabelecido entre o Projeto "ZL Vórtice" e o grupo de pesquisa DIGI-FAB da Faculdade de Arquitetura e Urbanismo da Universidade de São Paulo (FAUUSP) contribuiu decisivamente para a integração da tecnologia da pré-fabricação leve ao pensamento digital, ambos voltados à solução de problemas reais.

Em suma, pode-se dizer que o objetivo final da investigação aqui apresentada é oferecer às comunidades envolvidas as ferramentas e informações necessárias a fim de melhorar sua qualidade de vida, capazes de garantir seus direitos básicos 
de acesso à cidade, dentro de uma perspectiva emancipatória e de maior autonomia.

\section{Materiais e Métodos}

A inserção do projeto na realidade de uma cidade como São Paulo busca não apenas reproduzir os conceitos abordados na experiência ocorrida no Uruguai, mas também rever e adequar a proposta visando à democratização do acesso à informação e à aplicação dos processos construtivos nas condições específicas de cada local. Contando com a extensa rede pública de laboratórios de fabricação digital Fab Lab Livre SP, o grupo de pesquisa DIGI-FAB da FAUUSP vem trabalhando no redesenho das fôrmas para a galeria de microconcreto, de modo a que ela possa ser construída utilizando-se uma fresadora CNC de grande formato. Esse equipamento, assim como a impressora 3D, cortadora a laser, cortadora de vinil e fresadora de precisão, fazem parte do maquinário básico de um Fab Lab (nome derivado do termo em inglês Fabrication Laboratory), estando disponível em todos os laboratórios da rede mundial criada no início dos anos 2000, a partir da experiência do "Center for Bits and Atoms" no MIT - Massachusetts Institute of Technology (GERSHENFELD, 2005). Logo, o projeto das "Calçadas Drenantes" poderá ser replicado em qualquer laboratório de fabricação digital de São Paulo, bem como em qualquer Fab Lab do mundo, reforçando seu caráter colaborativo e aberto.

O produto deste trabalho, as fôrmas da galeria em microconcreto de alto desempenho, está sendo desenvolvido durante os Open Days do Fab Lab SP da FAUUSP - dia específico da semana aberto ao público externo à comunidade universitária -, quando seus integrantes, além de pesquisadores vindos de outras instituições de ensino e membros da comunidade, podem se reunir. O processo foi estudado com base em análises e discussões sobre as possibilidades de uso da pré-fabricação leve associada à manufatura digital, envolvendo a utilização da tecnologia do microconcreto de alto desempenho em obras de habitação de interesse social e infraestrutura urbana. Além disso, para cada etapa foram executados modelos em escala reduzida e programados experimentos práticos realizados no LAME Laboratório de Modelos e Ensaios - e no Fab Lab SP da FAUUSP, principalmente relacionados à prototipagem rápida das fôrmas e ao manuseio dos equipamentos de fabricação digital.

\section{Microconcreto de alto desempenho}

A nomenclatura microconcreto de alto desempenho tem sido adotada para descrever a técnica da argamassa armada ou ferro-cimento no contexto da pré-fabricação leve, destacandose aqui as mais recentes inovações tecnológicas alcançadas nos últimos 15 anos. Diferentemente dos concretos convencionais, a argamassa armada já apresentava um baixo fator água/cimento, limitado pela norma brasileira a 0,45 (NBR 11173, 1990). Essa característica confere ao material elevada resistência estrutural, propiciando a concepção de elementos pré-fabricados de pequena espessura - entre 20 e $30 \mathrm{~mm}$ em média - e, consequentemente, de pequena massa.
A transição da argamassa armada para o microconcreto de alto desempenho, ou microCAD, ocorre na medida em que são incorporados à sua composição aditivos superplastificantes que permitem a redução da quantidade de água na mistura, sem perda de trabalhabilidade, alcançando valores de aproximadamente 0,40 na relação água/aglomerante - aglomerante, pois considera-se a possibilidade de adição de materiais ligantes complementares ao cimento. Sendo 0,40 a fronteira entre concretos usuais e concretos de alto desempenho (FONSECA DE CAMPOS, 2017), o microCAD se apresenta como um material com grande potencial para uso na pré-fabricação leve, capaz de oferecer uma maior densidade tecnológica e valor agregado aos produtos.

A redução da quantidade de água na mistura, entretanto, busca não apenas o aumento de resistência estrutural, como também a diminuição da porosidade do composto. Ao obter uma matriz mais compacta e menos permeável, é possível impedir ou dificultar, consideravelmente, a penetração de agentes agressivos externos e aumentar a vida útil do microconcreto de alto desempenho. Ademais, adotam-se armaduras difusas - malhas de aço com fios finos e pouco espaçados entre si, fibras sintéticas ou naturais - que reforçam a estrutura e limitam a fissuração da matriz cimentícia.

Em um contexto de desigualdade e segregação sócioespacial, comum no ambiente urbano latino-americano, este trabalho adota como premissa o emprego da tecnologia do microCAD no desenvolvimento da pré-fabricação leve para obras de infraestrutura e habitação social. Dada a escassez de recursos públicos destinados às melhorias urbanas nas periferias, torna-se indispensável a busca por tecnologias acessíveis que visem a melhoria na qualidade de vida da população marginalizada e vulnerável.

Dentro dessa proposta, o microconcreto de alto desempenho se apresenta como uma alternativa economicamente viável. Graças à popularidade do concreto armado, os materiais necessários para a execução dos pré-fabricados leves podem ser encontrados facilmente em qualquer país. Ademais, a transferência de tecnologia é facilitada pelo conhecimento técnico prévio já acumulado em vários países da região, a exemplo do Brasil. Como resultado, o investimento inicial para a implantação de uma unidade de produção de elementos préfabricados em microconcreto, ou a adoção dessa tecnologia em empresas, é consideravelmente reduzido.

No entanto, o maior atrativo desse método construtivo é, possivelmente, a velocidade e facilidade de execução, viabilizando políticas públicas que sejam mais eficientes ao atender às demandas da população por melhorias urbanas. Devido à sua leveza, o transporte e manuseio dos elementos pré-fabricados dispensam o uso de máquinas de grande porte ou capacidade de carga. Nesse sentido, a pré-fabricação em microCAD se apresenta como uma tecnologia bastante apropriada para intervenções em assentamentos precários, na medida em que as obras têm um caráter menos invasivo e mais adequado ao contexto, pois podem considerar o tecido urbano existente. 


\section{Fabricação digital}

Ao contrário do que parece indicar o senso comum, as ferramentas de fabricação digital ou, mais precisamente, os equipamentos que operam através de Controle Numérico Computadorizado (CNC - Computer Numerical Control, no original em inglês), não são frutos de uma tecnologia recente, sendo que alguns possuem mais de 50 anos de existência. A primeira fresadora de controle numérico (NC - Numeric Control, no original em inglês) surgiu no final da década de 1940 no MIT com o intuito de facilitar a execução de peças de geometria complexa para a indústria aeronáutica e militar. Após duas décadas de desenvolvimento lento em virtude da baixa demanda fora da área governamental e da necessidade de computadores poderosos (e caros), o controle numérico computadorizado começa a se disseminar através de diversas áreas da manufatura apenas no final da década de 1960.

Em paralelo à disseminação dos computadores pessoais no começo da década de 1980 , as tecnologias de fabricação digital passaram a ter um alcance ainda maior, com o advento de sistemas de prototipagem rápida, como a estereolitografia, as cortadoras a laser e outros equipamentos de comando numérico que foram submetidos a um processo exponencial de miniaturização e aumento de potencial produtivo. Esse salto culminou, no final dos anos 2000 , com o aparecimento de máquinas CNC cuja operação, dimensões e custos eram muito mais acessíveis, passíveis de serem chamadas de equipamentos de fabricação pessoal (GERSHENFELD, 2005)

Analogamente à evolução no universo dos computadores que em 1950 ocupavam andares inteiros em edifícios e hoje são carregados no bolso - pode-se dizer que as máquinas de comando numérico que pesavam toneladas e se serviam de enormes mainframes, atualmente podem funcionar sobre a mesa de um escritório, conectadas a um computador pessoal como, por exemplo, uma impressora 3D.

A fabricação ou manufatura digital é o termo genérico que engloba processos distintos de manufatura que possuem 0 fato em comum de fazerem uso de equipamentos e máquinas CNC. Em linhas gerais, os processos de fabricação digital podem ser classificados como sendo aditivos, subtrativos ou conformativos.

Na manufatura aditiva, ou impressão 3D, o material de base é depositado por extrusão (filamentos termoplásticos ou materiais de base cimentícia), processado por sinterização a laser ou impresso por meio de aglutinantes aplicados sobre material em pó, camada sobre camada, sucessivamente, formando assim o objeto final. Os processos subtrativos ocorrem quando a conformação final do objeto é obtida pelo desbaste e retirada do material de base, como nos processos tradicionais de usinagem. Fresadoras, cortadoras a laser, jato d'água e plasma são alguns dos equipamentos mais utilizados nesse tipo de processo. Já nos processos conformativos o material de base não sofre desbaste, adição ou transformação de estado físico, mas sua forma é alterada diretamente pela deformação mecânica do material, utilizando-se para tanto uma calandra ou braços robóticos, por exemplo.
Em quaisquer dos processos de manufatura digital, sejam eles aditivos, subtrativos ou conformativos, a lógica é sempre a mesma: uma forma é gerada por computador (CAD Desenho/Projeto Auxiliado por Computador ou Computer Aided Design, no original em inglês) e nela são introduzidos os parâmetros pertinentes à sua fabricação (CAM Manufatura Auxiliada por Computador ou Computer Aided Manufacturing, no original em inglês). Após essa etapa o programa gera uma sequência de instruções numéricas, o Gcode (Código G, em português), que irá comandar um equipamento controlado por computador (CNC) de maneira a que ele execute todas as diferentes tarefas necessárias para a fabricação do objeto em questão.

Diferentemente das máquinas utilizadas na manufatura tradicional em série, que são ajustadas - e às vezes até mesmo fabricadas - para executar uma mesma tarefa específica indefinidamente, uma máquina CNC pode produzir objetos na escala de uma única unidade, pois, para esse equipamento flexível, não existem formas ou ajustes preestabelecidos, ele obedecerá às instruções contidas no Gcode, possibilitando assim um altíssimo grau de personalização ou customização.

\section{Processo de fabricação digital do produto}

O objeto de estudo, o sistema construtivo denominado "Calçadas Drenantes" (Figura 5), é composto por dois elementos principais: a galeria, peça pré-fabricada em microconcreto de alto desempenho, e a calçada propriamente dita, peça feita de concreto convencional. O projeto original concebido no âmbito do PIAI, vinculado ao MVOTMA do Uruguai, 2006 - consiste em três módulos de galeria: simples (1), com uma boca de lobo (2) e com duas bocas de lobo (3); que, montados com juntas a seco, configuram um sistema de galerias de microdrenagem superficial de águas pluviais (Figura 6). Adicionalmente, o conjunto pode exercer a função de canaleta de utilidades, abrigando tubulações de água, esgoto, entre outros serviços, e atendendo à demanda por uma infraestrutura urbana básica (Figura 7).

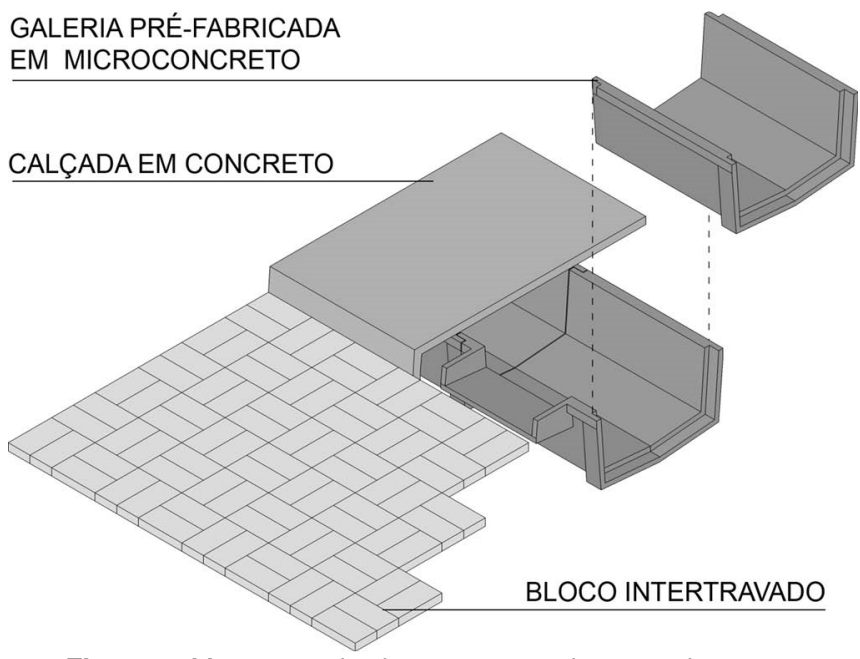

Figura 5: Montagem do sistema construtivo para drenagem superficial "Calçadas Drenantes". 


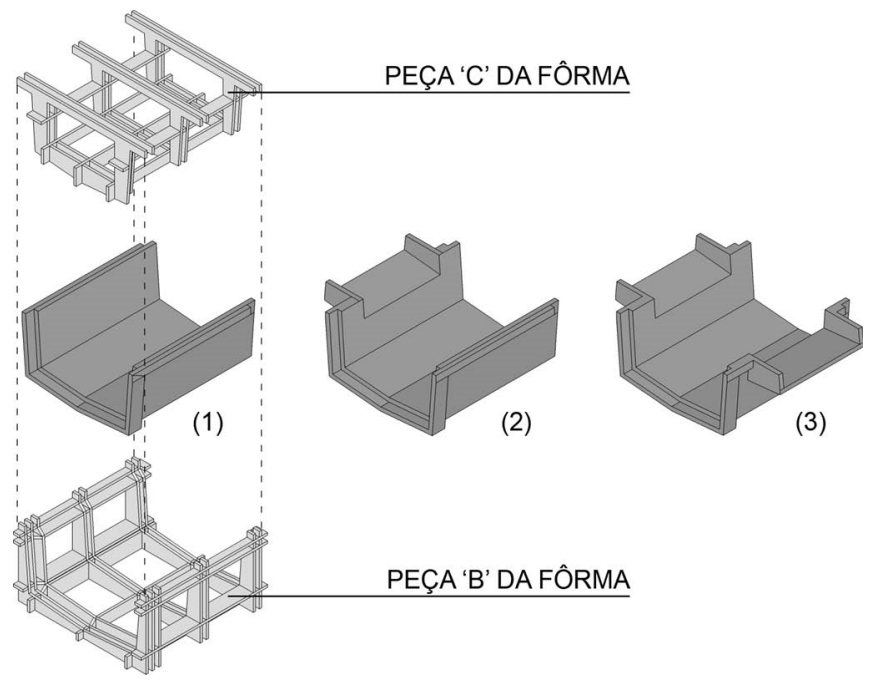

Figura 6: Módulos da galeria pré-fabricada em microCAD do projeto original, concebido no Uruguai: (1) simples; (2) com uma boca de lobo; (3) com duas bocas de lobo; e representação da montagem da fôrma em madeira, separada em duas peças: $\mathrm{B}$ e $\mathrm{C}$.
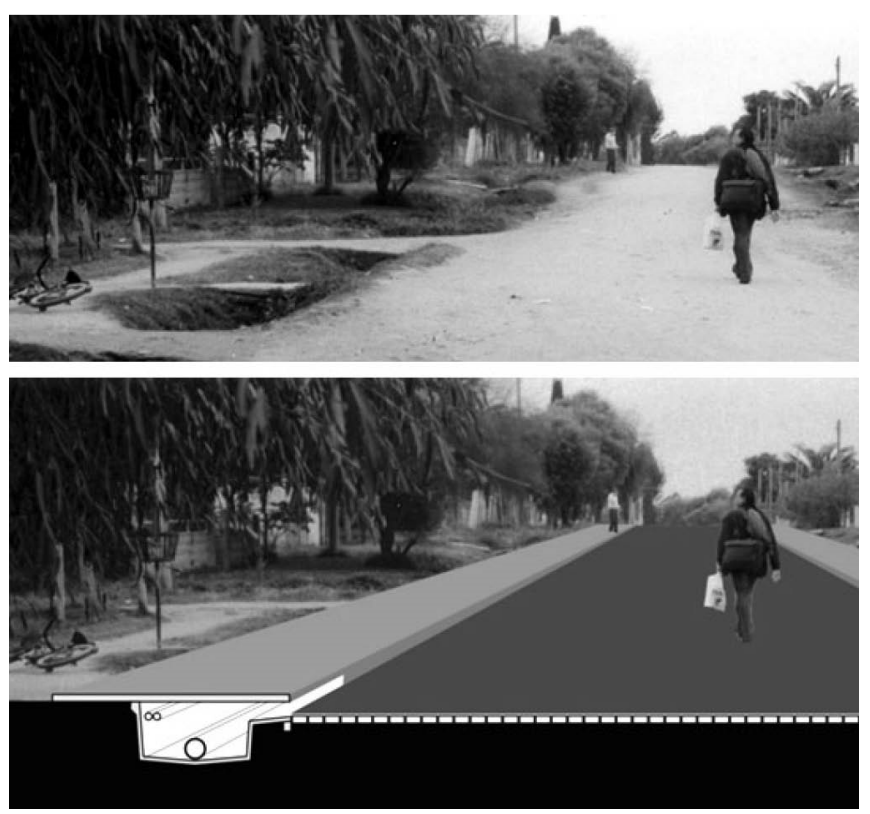

Figura 7: Fotomontagem representando a implantação do sistema "Calçadas Drenantes" de drenagem superficial em áreas de assentamento precário. Fonte: Paulo Eduardo Fonseca de Campos.

A recuperação deste projeto e sua implantação na cidade de São Paulo se deu com a incorporação dos instrumentos de fabricação digital, sendo o primeiro passo a adaptação da fôrma, originalmente em carpintaria tradicional, para a usinagem na fresadora CNC. Procurou-se manter a materialidade da fôrma, devido à tradição brasileira em utilizar madeira para moldar concreto armado in loco, adotando compensado naval de $18 \mathrm{~mm}$ de espessura como materialbase de ótima resistência estrutural e impermeabilidade. Com base no projeto uruguaio, o processo começou com o redesenho e prototipagem da fôrma para o módulo da galeria pré-fabricada em microconcreto sem nenhuma abertura, de geometria mais simples. A lógica aplicada era que, a partir desse modelo básico, seriam trabalhadas as galerias mais complexas, como os módulos que realizam curvas ou que possuem boca de lobo.

Os protótipos iniciais foram feitos com auxílio do programa de modelagem digital 123D Make, capaz de transformar objetos tridimensionais em 'fatias' 2D planificadas para a máquina de corte a laser. Entretanto, os modelos de organização das 'fatias' oferecidos pelo programa não eram os mais eficientes estruturalmente para o projeto, resultando no abandono dessa abordagem. Desse modo, o grupo de pesquisa DIGI-FAB se dedicou ao desenho manual da fôrma, utilizando-se do programa de computador Rhinoceros, "software de modelagem de superfícies NURBS (Non-Uniform Rational BSplines) que possibilita a proposição e visualização de superfícies de múltiplas curvaturas a partir da modelagem através de pontos de controle" (SOARES, 2013). Simulando o projeto em carpintaria tradicional, a fôrma foi separada em duas peças, nomeadas de peça $C$ e peça $B$ (Figura 6), que facilitariam o saque do elemento em microCAD depois de concretado. As peças foram desenvolvidas separadamente, porém seguindo a mesma lógica estrutural de encaixe 'machofêmea' das costelas de sustentação. Para a junção das partes da fôrma durante a concretagem foi pensado um sistema de fixação por barra roscada, onde as peças $\mathrm{B}$ e $\mathrm{C}$ seriam unidas pelo travamento de blocos de madeira fixados entre duas costelas de sustentação transversais, solução que exigiu a duplicação da estrutura.

Ao finalizar a modelagem digital dessa primeira proposta, foram realizadas duas maquetes na cortadora a laser: uma de papelão, na escala 1:6; e outra de MDF (Medium Density Fiberboard), na escala 1:3. Ainda que tenha sido feita com um material diferente, a maquete em papelão induziu análises estruturais importantes, como a necessidade de um travamento horizontal para a peça $\mathrm{C}$ que impedisse maiores deformações. Enquanto a peça $C$ ia sendo redesenhada, 0 grupo focou no modelo em MDF da peça B (Figura 8) que, simulando o comportamento do material e os encaixes das costelas, apresentou um bom desempenho funcional e indicou a continuidade dessa abordagem estrutural. Em contrapartida, esse ensaio expôs de forma clara um problema comum à produção de fôrmas de madeira com ângulos obtusos ou agudos: o topo das chapas de compensado que formam a geometria da galeria em microconcreto precisa ser aplainado em ângulo (Figura 9), para que se crie um encaixe preciso, apropriado para a concretagem. Devido à pequena dimensão das placas de MDF na escala adotada para o modelo, o chanfro foi feito com uma lixadeira elétrica, processo manual e demorado que resultou em ângulos aproximados e encaixes sem precisão. Desse modo, ficou evidente a necessidade de se resolver o chanframento na própria fresadora, uma vez que a realização desse trabalho manualmente demandaria um esforço adicional que contradiz a introdução da fabricação digital no projeto. 


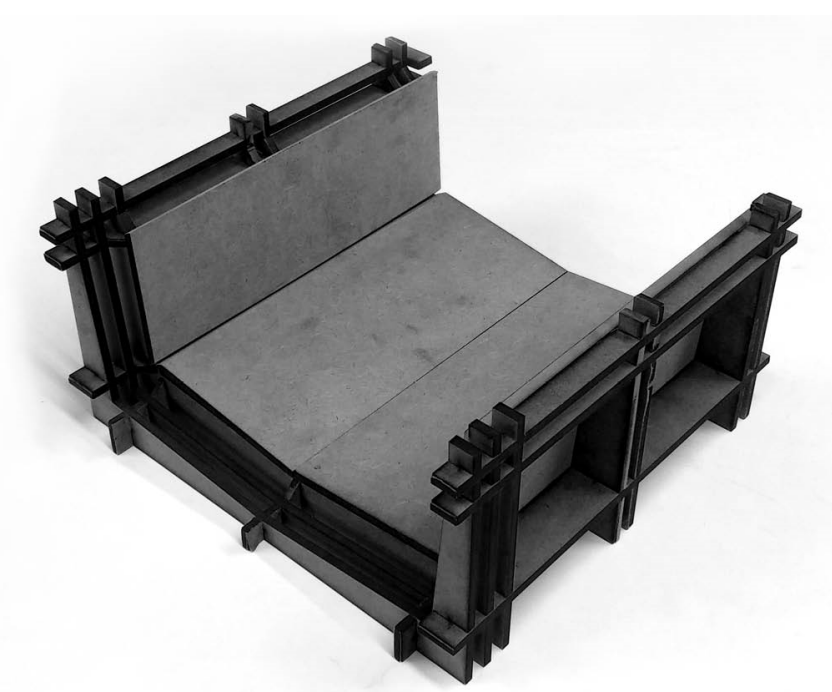

Figura 8: Modelo de estudo da peça $B$ da fôrma em MDF, na escala $1: 3$, realizado na cortadora a laser.

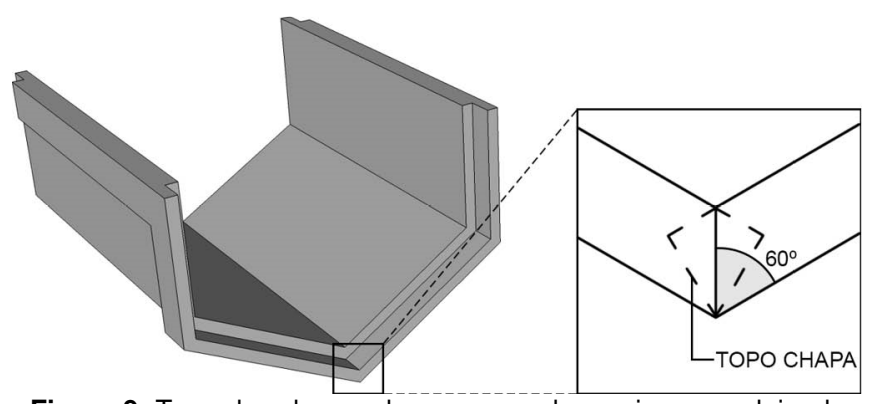

Figura 9: Topo das chapas de compensado precisa ser aplainado em ângulo (representação do módulo redesenhado).

Prosseguindo com o desenvolvimento da fôrma, um novo protótipo em papelão foi executado, conforme as alterações realizadas na peça $C$. Esse modelo físico, por ser leve e pequeno, foi levado para diversas reuniões externas e apresentado para o público em geral: professores, estudantes, moradores das comunidades-alvo, líderes comunitários e profissionais de outras áreas. Observou-se que, ao interagir com o modelo, várias pessoas encaixavam as peças $\mathrm{C}$ e $\mathrm{B}$ com as costelas intercaladas, e não sobrepostas. Tal comportamento deu indícios de que era necessário rever o método de união das partes, adotando uma solução mais intuitiva na montagem. Pensar em um método onde as próprias costelas funcionassem como ponto de ancoragem para junção resultaria em uma estrutura mais econômica, uma vez que não seriam necessários os blocos de travamento e as costelas duplicadas.

\section{Resultados e Discussão}

O processo de redesenho das fôrmas para a sua adequação ao processo de fabricação digital envolveu uma série de modificações em função do modelo produtivo escolhido. Alterações que, sem a experimentação prática nesta fase inicial do trabalho, seriam feitas apenas em etapas futuras e demandariam maior esforço e custo. Visto que a introdução da fabricação digital no projeto visa alcançar uma produção mais eficiente das fôrmas - precisa, rápida e com economia de recursos -, considerou-se a hipótese de que os moldes de madeira sejam usinados integralmente na fresadora CNC, saindo prontos para a montagem. Para tal, o estudo das juntas entre as chapas de que constituem a superfície das fôrmas deve estar incluído nesse processo de desenvolvimento, sem depender de outros equipamentos ou processos manuais para sua finalização. A solução encontrada para essa questão foi a adequação da geometria da galeria pré-fabricada em microCAD para que se pudesse utilizar uma fresa de chanfro angular na realização do corte das placas.

Levando em consideração a espessura de $18 \mathrm{~mm}$ do compensado naval utilizado, foi necessário adotar uma fresa de ângulo mais fechado, capaz de atravessar toda a placa e realizar o corte. Após alguns estudos com fresas de chanfro comerciais, adotou-se a de 60 graus de ângulo. No entanto, ao estabelecer um ângulo fixo de inclinação para a fresagem dos topos das chapas de fôrma, altera-se o ângulo de saque da peça a ser moldada e, consequentemente, a geometria final do elemento pré-fabricado. Como resultado, a galeria foi redesenhada para a utilização da fresa de chanfro angular (Figuras 9 e 10), com o objetivo de simplificar a usinagem das peças e tornar o processo de produção coeso, utilizando apenas a fresadora $\mathrm{CNC}$, sem a necessidade de pós processamento manual nas fôrmas.

Analisando o processo de projeto até então, é possível reconhecer a prototipagem rápida como prática determinante no desenvolvimento do produto. A elaboração de modelos físicos, além de auxiliar na análise formal e funcional do objeto, facilita a interação do mesmo com o público-alvo e profissionais de outras áreas do conhecimento, como foi observado nas visitas das comunidades envolvidas ao Fab Lab SP da FAUUSP e nas reuniões com membros do setor público e sociedade civil. Ademais, a utilização das máquinas de fabricação digital durante o desenvolvimento do projeto ajuda a reconhecer o processo de produção como um todo, incorporando aspectos técnicos e de funcionamento do equipamento no design final do objeto. Como exemplo desse processo, pode-se citar a adoção da fresa de chanfro angular para o corte das chapas de superfície dos moldes, solução que alterou a geometria da galeria.

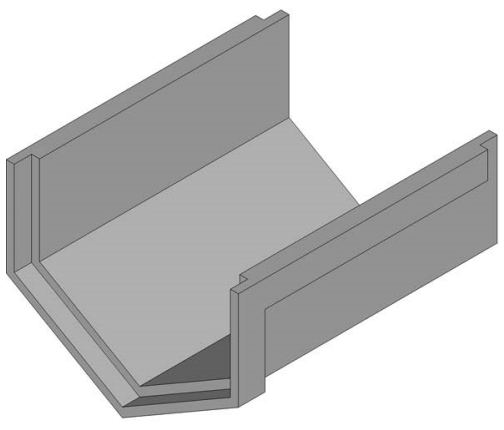

MÓDULO NOVO

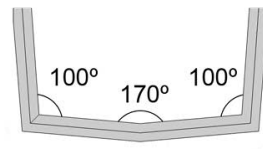

MÓDULO ORIGINAL

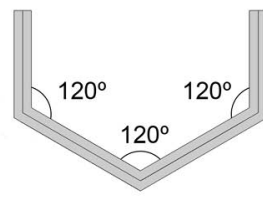

MÓDULO NOVO
Figura 10: Módulo da galeria pré-fabricada em microCAD adaptado para o uso de uma fresa de chanfro angular em comparação com o módulo original concebido no Uruguai, em 2006. 
A introdução da fabricação digital na produção dos elementos pré-fabricados leves em microconcreto, além de dispensar o uso de mão-de-obra especializada (carpinteiro ou marceneiro) na construção das fôrmas de madeira, possibilita a capacitação da população de modo que ela se aproprie integralmente dos modelos produtivos. Em seu formato atual, o projeto consiste na implantação de canteiros experimentais de pré-fabricação leve em microconcreto nas comunidadesalvo - Jardim Lapenna e Jardim Pantanal -, onde serão produzidos os componentes para montagem da calçada drenante. Esses canteiros serão espaços de trabalho e formação, criados pelas comunidades em terrenos disponíveis e equipados com o ferramental básico. São locais de experimentação e, sobretudo, de troca de saberes entre técnicos e moradores. Supõe-se que o canteiro seja o embrião de unidades de produção comunitária de componentes construtivos pré-fabricados leves, como os CPCs da proposta uruguaia, permitindo a disseminação das tecnologias adaptadas e a capacitação da mão-de-obra local. Além disso, espera-se promover melhorias urbanas aliadas a um processo de desenvolvimento local, com geração de emprego e renda, fomentado pela autogestão e produção comunitária.

A proposta se viabiliza também devido à implantação recente dos Fab Labs Livres SP da Prefeitura de São Paulo que, como laboratórios públicos, têm como principal objetivo a capacitação e conscientização da população em relação às tecnologias de manufatura digital, incentivando a realização de projetos colaborativos que buscam soluções para problemáticas locais. Nesse sentido, a lógica do canteiro experimental se estende até o ambiente do Fab Lab, uma vez que esse espaço oferece cursos gratuitos voltados para a formação técnica, facilitando a transferência do conhecimento e, consequentemente, o processo de apropriação dos meios de produção pelos moradores das comunidades.

Nesse contexto, as atividades realizadas no Fab Lab SP da FAUUSP e nos Fab Labs Livres SP da prefeitura situados na Zona Leste de São Paulo (CEU Três Pontes, Itaquera e Cidade Tiradentes) irão desenvolver um tipo complementar de pesquisa, produção e formação, focados na modelagem e fabricação digitais. Acredita-se que a médio prazo, esse vínculo com os Fab Labs pode gerar novas iniciativas de melhoramentos nas comunidades e parcerias com grupos de extensão e pesquisa universitários. Assim, busca-se um meio da universidade atuar em convergência com as demais políticas públicas voltadas para a região, integrando-as com iniciativas da sociedade civil e procurando efetivar iniciativas de cunho inovador que confirmem seu compromisso com o interesse social.

Em ambos os casos, a transferência de conhecimento é percebida através da lógica de emancipação por meio da democratização do acesso à tecnologia. A emancipação, nesse sentido, pode ser entendida como uma possibilidade de transformação socioeconômica e ambiental, uma vez que a tecnologia apropriada e a experiência de autogestão oferecem às comunidades envolvidas a oportunidade de transformar 0 habitat em que vivem por sua própria iniciativa, atendendo às demandas locais e melhorando a qualidade de vida da população residente. Além disso, possibilita a geração de emprego e renda através da implantação da lógica do empreendedorismo, configurando um polo econômico alternativo apropriado frente à crise econômica e às altas taxas de desemprego no país. Em outras palavras, procura-se construir uma sociedade resiliente, capaz de se adaptar e procurar soluções para superar a vulnerabilidade.

Através dessa experiência foi possível analisar o papel do arquiteto e do designer como catalisadores de intervenções de cunho social, desenvolvendo soluções técnicas passíveis de aplicação e apropriação por movimentos organizados. A finalidade do projeto é a de viabilizar a transformação do habitat pelos próprios usuários, mudando a forma com que eles percebem e interagem com o ambiente construído. Para tal, é preciso que a mobilização tenha origem na própria comunidade, a partir de demandas reais, atribuindo ao projetista, arquiteto ou designer, a função de apoio e assessoria técnica, onde a tecnologia concebida atua como coadjuvante do processo social.

Por fim, considerando que este é um trabalho em andamento, vale destacar que os resultados, assim como as discussões, ainda estão em progresso. Dando continuidade à proposta, os próximos passos serão a conclusão do desenvolvimento da fôrma para a galeria pré-fabricada em microconcreto, focando na exploração material das fresas de chanfro angular, e a execução do protótipo em escala 1:1 no Fab Lab SP que servirá de demonstração para os moradores das comunidades-alvo. A implantação dos canteiros experimentais já está sendo discutida com os movimentos organizados locais e a coordenação da rede Fab Lab Livre SP já demonstrou interesse em colaborar com a proposta. A expectativa é que, com o êxito do projeto "Calçadas Drenantes", apareçam novas oportunidades de demonstrar que a inovação e tecnologia têm espaço para produzir soluções alternativas adequadas.

\section{Considerações Finais}

Analisando o contexto da América Latina, onde a segregação social e territorial das cidades se sobrepõem, questões como a otimização do espaço urbano, habitabilidade e sustentabilidade da habitação social são os maiores desafios a se alcançar (FONSECA DE CAMPOS, 2013). Entretanto, a prática adotada pelos governos é a de utilizar métodos conservadores de gestão e construção para intervir em assentamentos precários, que apresentam uma organização social e espacial diferentes da cidade formal. Frente à incapacidade do Estado em oferecer soluções apropriadas para a população marginalizada, reafirma-se a importância em pensar alternativas para promover melhorias na qualidade de vida desses grupos vulneráveis nas grandes cidades latinoamericanas.

O projeto "Calçadas Drenantes" se apresenta, dentro desse cenário, como uma proposta que une a credibilidade e experiência acumulada com 0 microconcreto de alto desempenho com a flexibilidade e capacidade das ferramentas de fabricação digital, em busca de uma solução tecnológica apropriada para áreas periféricas e em situação de vulnerabilidade. Não obstante, tal solução deve ser capaz 
de coadjuvar processos liderados por movimentos sociais organizados, que possam implementar propostas que confirmem seu compromisso social com a comunidade.

Mesmo em andamento, o trabalho vem demostrando um potencial transformador, principalmente aliado a uma rede pública cujo objetivo é incentivar a inovação local através de uma lógica emancipadora, como é o caso da rede Fab Lab Livre SP. Os laboratórios de fabricação digital, verdadeiros espaços de produção colaborativa e educação não-formal, conformaram pontos de apoio para a elaboração da proposta, tanto no processo de desenvolvimento de produto, no Fab Lab SP da FAUUSP, como na implantação integral do projeto, nos Fab Labs da rede pública. Diante desse vínculo, espera-se que, a partir do regime de capacitação e transferência de tecnologia adotado no "Calçadas Drenantes", novas iniciativas de projetos colaborativos surjam.

\section{Agradecimentos}

Agradecemos ao Projeto "ZL Vórtice" pela oportunidade e colaboração no desenvolvimento do projeto como um todo.

\section{Referências}

ADVFN Brasil. (2017). Indicadores econômicos - Pnad. Retrieved from http://br.advfn.com/indicadores/pnad

Associação Brasileira de Normas Técnicas. (1990). Projeto e execução de argamassa armada: NBR 11173. Rio de Janeiro.
Cardoso, R. (2012) Design para um mundo complexo. São Paulo: Cosac Naify.

Fonseca de Campos, P. E. (2013). Microconcreto de Alto Desempeño: La tecnologia del MicroCAD aplicada em la construcción del hábitat social, São Paulo: Mandarim.

Fonseca De Campos, P. E. (2017). Tecnologias para a construção do Habitat Social: O microconcreto de alto desempenho para 0 desenvolvimento da pré-fabricação leve. In: CIHEL - Congresso Internacional de Habitação no Espaço Lusófono. $4^{\circ}$ Ed. Covilhã, Portugal.

Franco, F. M. (2005). A construção do caminho: a estruturação da metrópole pela conformação técnica das várzeas e planícies fluviais da Bacia de São Paulo (Tese de doutorado). São Paulo, FAU USP

Gershenfeld, N. (2005). FAB: The coming revolution on your desktop - From personal computers to personal fabrication. Cambridge, MA: Basic Books.

Instituto Trata Brasil, Fundação Getúlio Vargas. (2010). Benefícios Econômicos da Expansão do Saneamento Brasileiro.

Ladivez, V. H. L. (2016). EducLab: O impacto das tecnologias de fabricação digital sobre o ensino em nível fundamental II e médio (Trabalho de Conclusão de Curso). São Paulo, FAU USP.

Mascaró, J. L., Yoshinaga, M. (2005). Infraestrutura urbana. Porto Alegre: Masquatro Editora.

Soares, J. P. (2013). Processo de Design em Arquitetura: Complexidade e meios digitais (Dissertação de Mestrado). São Carlos, IAU USP. 